\title{
Effects of Soybean/Brown Rice Consumption on Body Fat and Blood Lipids in Overweight Postmenopausal Women
}

\author{
Tsan-Hon Liou', Hui-Wen Kao², Yi-Chun Hsueh², Yi-Wen Chien ${ }^{2 *}$
}

${ }^{1}$ Obesity Research Center and Department of Physical Medicine and Rehabilitation, Taipei Medical University-Shuang Ho Hospital, Taipei, Taiwan; Graduate Institute of Injury Prevention, Taipei Medical University, Taipei, Taiwan, Republic of China

${ }^{2}$ Taipei Medical University, School of Nutrition and Health Sciences, Taipei, Taiwan, Republic of China

\section{Received Date: Feb 5, 2015 Accepted Date: April 9, 2015 Published Date: April 16, 2015}

Correspondingauthor: Yi-WenChien, School of Nutrition and Health Sciences, Taipei Medical University, Taipei, Taiwan, Republic of China. Tel: 886-2-27361661\#6556; Fax: 886-2-2737-3112; E-mail: ychien@tmu.edu.tw

Citation: Yi-Wen Chien. et al. Effects of Soybean/Brown Rice Consumption on Body Fat and Blood Lipids in Overweight Postmenopausal Women. (2015) J Food Nutr Sci 2(1): 64-69.

Keywords: Postmenopausal women; Soybean; Brown Rice, Body fat, Serum cholesterol

\section{Introduction}

A menopause-induced estrogen deficiency is related to body weight and fat gains. Abdominal fat increases as a result of fat redistribution after menopause. The waist circumference (WC) is higher than that of premenopausal women ${ }^{[1]}$. Insulin resistance and abnormal plasma glucose and lipid levels were found, and may contribute to a high risk of cardiovascular disease (CVD) in postmenopausal women ${ }^{[2]}$. Hormone-replacement therapy (HRT) has beneficial effects on the body composition and blood profiles ${ }^{[3]}$, whereas HRT may also have some adverse health effects ${ }^{[4]}$.

Soybeans are a traditional Asian food. Soy food intake is negatively associated with waist circumference (WC) and diabetes risk $^{[5,6]}$. Structures of isoflavones are similar to that of estrogen $^{[7]}$. Isoflavones can prevent body fat gain in ovariectomized female rats, an animal model of menopause ${ }^{[8]}$. Soy protein and isoflavones can decrease plasma cholesterol and plasma glucose and reverse insulin resistance in both animal and clinical studies $^{[9,10]}$. Soybeans contain some beneficial components for lowering cholesterol levels such as saponins and phytosterols ${ }^{[11]}$.

Whole grains are rich in dietary fiber, vitamins, minerals, and antioxidants. Ingestion of whole grains is positively associated with lower serum cholesterol, blood pressure, and insulin sensitivity ${ }^{[12,13]}$. The risks of metabolic syndrome and CVDs were lower in subjects who ingested three servings of whole grains per day ${ }^{[14]}$. Thus, in the present study, we assessed the effects of soybean/brown rice (SBR) on anthropometric profiles, body composition, and blood profiles in postmenopausal women.

\section{Subjects and Methods}

\section{Participants}

In total, 34 postmenopausal women were screened for inclusion in the study. Subjects were ethnic Chinese (i.e., Taiwanese) menopausal women who had not had a menstrual cycle for at least 1 year, with serum follicle-stimulating hormone (FSH) level of $>40 \mathrm{IU}$, estradiol (E2) of $<30 \mathrm{pg} / \mathrm{mL}$, and a body-mass index (BMI) of $>24 \mathrm{~kg} / \mathrm{m}^{2}$. Exclusion criteria were any unnatural features of menopause, the uterus, or ovaries, untreated hypothyroidism, kidney or liver diseases, current or previous (in the preceding $6 \mathrm{mo}$ ) use of estrogen therapy, treatment with insulin or oral hypoglycemic agents, smoking, malignancy, or cancer. Those with an allergy to soybeans, brown rice, or rice bran were also excluded.

Copy rights: (C2015 Yi-Wen Chien. This is an Open access article distributed under the terms of Creative Commons Attribution 


\section{Study Design}

The study was carried out strictly in accordance with ethical standards as outlined by Taipei Medical University. After screening with exclusion criteria and some withdrew due to allergy, in total, 23 overweight postmenopausal women were included and were randomly divided into two groups: an SBR group and a control group. The study intervention was 12 weeks, and anthropometric measurements, body composition, blood pressure, and blood profiles of subjects were measured at the baseline ( 0 week) and at 12 weeks.

\section{Dietary Intervention}

Two groups received diets restricted to $1200 \mathrm{kcal}$ of energy. Subjects ingested one package of SBR as their grains at lunch in the SBR group. There was $213.1 \pm 3.8 \mathrm{~g}$ of SBR per package which included $138.0 \pm 12.7 \mathrm{~g}$ brown rice and 75.1 $\pm 10.1 \mathrm{~g}$ soybeans. The nutritional composition and isoflavone contents were analyzed by the Food Industry Research and Development Institute (FIDI, city, Taiwan) (Tables 1,2). Subjects consumed their habitual diets and received one-on-one dietary directions from a dietitian. They were asked to record 3 days of dietary intake including 2 weekdays and 1 weekend day at the baseline and at 12 weeks. Dietary nutritional intake was analyzed by E kitchen software.

Table 1: Nutritional composition of the soybean/brown rice used in the intervention ${ }^{1}$

\begin{tabular}{|c|c|}
\hline Nutrient & Soybean/brown rice \\
\hline Calories $(\mathrm{kcal})$ & $304.8 \pm 5.4$ \\
\hline Carbohydrates $(\mathrm{g})$ & $42.7 \pm 0.8$ \\
\hline Crude fat $(\mathrm{g})$ & $8.2 \pm 0.1$ \\
\hline Crude proteins $(\mathrm{g})$ & $15.1 \pm 0.3$ \\
\hline Crude fiber $(\mathrm{g})$ & $4.7 \pm 0.1$ \\
\hline Total dietary fiber $(\mathrm{g})$ & $10.3 \pm 0.2$ \\
\hline Moisture $(\mathrm{g})$ & $140.7 \pm 2.5$ \\
\hline
\end{tabular}

${ }^{1}$ Amounts are per $213.1 \pm 3.8 \mathrm{~g}$.

Table 2: Crude protein and isoflavone contents in soybeans of the soybean/ brown rice

\begin{tabular}{|c|c|}
\hline & Soybeans \\
\hline Crude protein $(\mathrm{g})$ & $8.7 \pm 1.2$ \\
\hline Isoflavones $(\mathrm{mg})$ & $22.0 \pm 3.0$ \\
\hline Genistin $(\mathrm{mg})$ & $11.17 \pm 1.51$ \\
\hline Daidzin $(\mathrm{mg})$ & $4.19 \pm 0.57$ \\
\hline Glycitin $(\mathrm{mg})$ & $0.47 \pm 0.06$ \\
\hline Genistein $(\mathrm{mg})$ & $3.23 \pm 0.44$ \\
\hline Daidzein $(\mathrm{mg})$ & $1.55 \pm 0.21$ \\
\hline Glycitein $(\mathrm{mg})$ & $0.12 \pm 0.02$ \\
\hline
\end{tabular}

${ }^{1}$ Soybeans in soybean/brown rice were $75.1 \pm 10.1 \mathrm{~g}$.

\section{Measurements}

\section{Anthropometrics and Blood Pressure}

Height was measured in a standing position without shoes using a wall-mounted stadiometer. The body weight (BW), $\mathrm{BMI}$, and basal metabolic rate (BMR) were measured with an In Body 3.0 Body Composition Analyzer. The waist circumference
(WC) was measured at the level midway between the lower rib margin and the iliac crest using a non-elastic tape with no pressure on the body surface. Hip circumference (HC) was measured at the level of the greater trochanters. Blood pressure was measured with a sphygmomanometer.

\section{Body Composition}

Body-fat weight (BF), lean body mass weight (LBM), total body-fat percentage (total BF), android-fat percentage (Android), gynoid fat percentage (Gynoid), and android to gynoid fat percentage ratio (A/G ratio) were measured by dual-energy $\mathrm{x}$-ray absorptiometry (DEXA).

\section{Blood Profiles}

After a 24-h fast, blood samples were collected and centrifuged at $3000 \mathrm{rpm}$ for $15 \mathrm{~min}$ at $4{ }^{\circ} \mathrm{C}$ to separate the plasma. Serum FSH, $\mathrm{E}_{2}$, and insulin concentrations were measured by a chemi luminescence immunoassay using an auto analyzer (Siemens Centaur, Germany). Serum total cholesterol (TC) and [triacylglycerol/triglyceride?] (TG) concentrations were measured by an enzymatic method (ref?). Low- (LDL-C) and high-density lipoprotein cholesterol (HDL-C) were measured by an elimination/catalase method. Blood glucose was measured by an enzymatic colorimetric method using hexokinase. The insulin resistance was calculated using the homeostasis model assessment method (HOMA-IR $=$ insulin $\times$ glucose/22.5), and the insulin sensitivity was calculated using the quantitative insulin sensitivity check index (QUICKI $=1 /(\log$ insulin $+\log$ glycemia). Serum leptin and adiponectin concentrations were measured by a radioimmunoassay. Plasma isoflavone contents were measured by high-performance liquid chromatography (HPLC). Plasma samples were treated with a $\beta$-glucuronidase/sulfatase mixture to hydrolyze glucuronide and sulfate conjugates of isoflavones. After vortex-mixing for $30 \mathrm{~s}$ and centrifugation at 13,000 rpm for $5 \mathrm{~min}$, plasma was purified using a solid-phase extraction cartridge. Plasma was purified by the method of Anupongsanugool et al. ${ }^{[15]}$ Plasma samples were frozen and stored at $-80^{\circ} \mathrm{C}$ until being analyzed by HPLC. The HPLC analysis was performed using an autosampler (Hitachi Autosampler L-7200, Hitachi Dump L-7100, Japan) and detected by ultraviolet absorption at $250 \mathrm{~nm}$ (Hitachi Diode Array Detector L-7455). The

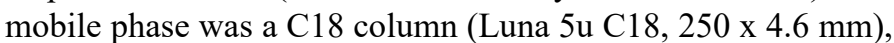
and the reverse phase consisted of $100 \%$ acetonitrile (A) and 10 $\mathrm{mM}$ ammonium acetate (B).

\section{Statistical Analysis}

All data are presented as the mean \pm standard deviation (SD). Data were compared between the SBR and control groups using Student's t-test at the baseline ( 0 week) and at 12 weeks. We compared the baseline and 12-week data within groups using a paired $t$-test. Statistical analyses were performed using SAS vers. 9.1.3 (Cary, NC, USA). $p$ values of $<0.05$ were considered significant.

\section{Results}

\section{Subject Characteristics}

Twenty-three postmenopausal women were enrolled in this study, 11 in the control group and 12 in the SBR group. FSH concentrations were $>40 \mathrm{IU} / \mathrm{L}$ and $\mathrm{E} 2$ concentrations were $<30$ 
$\mathrm{pg} / \mathrm{mL}$ in all subjects. At the baseline, BWs were $63.9 \pm 9.7$ and $62.7 \pm 5.4 \mathrm{~kg}$ and BMIs were $26.4 \pm 3.1$ and $25.6 \pm 1.7 \mathrm{~kg} / \mathrm{m}^{2}$, respectively (Table 3 ).

Table 3: Baseline characteristics of subjects ${ }^{1}$

\begin{tabular}{|c|c|c|}
\hline & Control & Soybean/brown rice \\
\hline Number & 11 & 12 \\
\hline Age (year) & $59.2 \pm 5.5$ & $57.0 \pm 3.0$ \\
\hline Height $(\mathrm{cm})$ & $155.4 \pm 6.3$ & $156.5 \pm 6.2$ \\
\hline Body weight $(\mathrm{kg})$ & $63.9 \pm 9.7$ & $62.7 \pm 5.4$ \\
\hline Body-mass index $\left(\mathrm{kg} / \mathrm{m}^{2}\right)$ & $26.4 \pm 3.1$ & $25.6 \pm 1.7$ \\
\hline Waist circumference $(\mathrm{cm})$ & $88.7 \pm 6.3$ & $88.5 \pm 3.4$ \\
\hline Hip circumference $(\mathrm{cm})$ & $104.4 \pm 7.3$ & $102.2 \pm 4.0$ \\
\hline Waist/hip ratio & $0.85 \pm 0.05$ & $0.87 \pm 0.04$ \\
\hline $\begin{array}{c}\text { Follicle-stimulating hormone } \\
\text { (mIU/mL) }\end{array}$ & $71.7 \pm 24.0$ & $62.7 \pm 11.5$ \\
\hline Estradiol (pg/mL) & $29.2 \pm 6.3$ & $25.9 \pm 11.7$ \\
\hline
\end{tabular}

${ }^{1}$ Data are expressed as the mean $\pm \mathrm{SD}$.

\section{Dietary Intake}

There were no significant differences between the control and SBR groups in the contents of energy, macronutrients, or dietary fiber at the baseline. However, after the 12-week intervention, energy (1226.4 \pm 222.6 vs. $1149.8 \pm 164.9 \mathrm{kcal}$, respectively) and carbohydrate intake were significantly lower than at the baseline $(p<0.05)$. Dietary fiber intake had significantly increased in the SBR group and was also higher than that of the control group $(p<0.05)$ (Table 4$)$.

Table 4: Daily energy, macronutrient, and dietary fiber intake by postmenopausal women ${ }^{1}$

\begin{tabular}{|c|c|c|c|}
\hline & Control $(n=11)$ & $\begin{array}{l}\text { Soybean/brown } \\
\text { rice }(n=12)\end{array}$ & $\mathrm{p}$ value ${ }^{2}$ \\
\hline \multicolumn{4}{|c|}{ Energy (kcal) } \\
\hline 0 week & $1507.7 \pm 345.7$ & $1492.4 \pm 306.0$ & 0.4384 \\
\hline 12 weeks & $1226.4 \pm 222.6 *$ & $1149.8 \pm 164.9 *$ & 0.2313 \\
\hline \multicolumn{4}{|c|}{ Protein (\% Energy) } \\
\hline 0 week & $15.7 \pm 4.1$ & $16.2 \pm 2.4$ & 0.4591 \\
\hline 12 weeks & $18.6 \pm 3.9$ & $18.0 \pm 3.0$ & 0.7248 \\
\hline \multicolumn{4}{|c|}{ Fat (\% Energy) } \\
\hline 0 week & $31.5 \pm 9.5$ & $31.6 \pm 3.2$ & 0.9864 \\
\hline 12 weeks & $38.8 \pm 5.3$ & $36.2 \pm 5.8$ & 0.2862 \\
\hline \multicolumn{4}{|c|}{ Carbohydrates ( $\%$ Energy) } \\
\hline 0 week & $52.7 \pm 12.8$ & $52.2 \pm 3.0$ & 0.9158 \\
\hline 12 weeks & $42.6 \pm 5.8 *$ & $44.2 \pm 4.7 *$ & 0.7513 \\
\hline \multicolumn{4}{|c|}{ Dietary fiber (g) } \\
\hline 0 week & $18.6 \pm 11.1$ & $18.7 \pm 7.5$ & 0.7246 \\
\hline 12 weeks & $15.6 \pm 3.8$ & $21.5 \pm 5.7 *$ & 0.0289 \\
\hline
\end{tabular}

${ }^{1}$ Data are expressed as the mean $\pm \mathrm{SD}$.

${ }^{2}$ Differences between the two groups in the same week.

*Significantly differs between 0 and 12 weeks in the same group, $p<0.05$.

\section{Effects of SBR on Anthropometric Measurements and Blood Pressure}

Anthropometric measurements and blood pressure data are shown in Table 5. At 12 weeks, the BW, BMI, WC, $\mathrm{HC}, \mathrm{WHR}$, and BMR were significantly reduced in both groups $(p<0.05)$, but there were no significant differences between groups. In contrast, DBP was significantly reduced at 12 weeks in the SBR group and was significantly lower than that of the control group $(p<0.05)$.

Table 5: Anthropometric measurements and blood pressure in groups during the intervention period ${ }^{1}$

\begin{tabular}{|c|c|c|c|}
\hline & Control $(n=11)$ & $\begin{array}{l}\text { Soybean/brown } \\
\text { rice }(n=12)\end{array}$ & $\mathrm{p}$ value $^{2}$ \\
\hline \multicolumn{4}{|c|}{ Body weight (kg) } \\
\hline 0 week & $63.9 \pm 9.7$ & $62.7 \pm 5.4$ & 0.6008 \\
\hline 12 weeks & $60.8 \pm 10.0 *$ & $59.5 \pm 4.9 *$ & 0.8535 \\
\hline \multicolumn{4}{|c|}{ Body-mass index $\left(\mathrm{kg} / \mathrm{m}^{2}\right)$} \\
\hline 0 week & $26.4 \pm 3.1$ & $25.6 \pm 1.7$ & 0.6888 \\
\hline 12 weeks & $25.1 \pm 3.4 *$ & $24.3 \pm 1.9 *$ & 0.8288 \\
\hline \multicolumn{4}{|c|}{ Waist circumference $(\mathrm{cm})$} \\
\hline 0 week & $88.7 \pm 6.3$ & $88.5 \pm 3.4$ & 0.9181 \\
\hline 12 weeks & $80.3 \pm 7.7 *$ & $81.4 \pm 2.9 *$ & 0.9079 \\
\hline \multicolumn{4}{|c|}{ Hip circumference $(\mathrm{cm})$} \\
\hline 0 week & $104.4 \pm 7.3$ & $102.2 \pm 4.0$ & 0.3918 \\
\hline 12 weeks & $99.8 \pm 7.3 *$ & $99.2 \pm 4.6 *$ & 0.5525 \\
\hline \multicolumn{4}{|c|}{ Waist/hip ratio } \\
\hline 0 week & $0.85 \pm 0.05$ & $0.87 \pm 0.04$ & 0.3529 \\
\hline 12 weeks & $0.80 \pm 0.04 *$ & $0.82 \pm 0.04 *$ & 0.5374 \\
\hline \multicolumn{4}{|c|}{ BMR (kcal) } \\
\hline 0 week & $1126.3 \pm 83.1$ & $1124.9 \pm 79.8$ & 0.9654 \\
\hline 12 weeks & $1106.0 \pm 83.1 *$ & $1113.0 \pm 73.0 *$ & 0.7251 \\
\hline \multicolumn{4}{|c|}{$\mathrm{SBP}(\mathrm{mmHg})$} \\
\hline 0 week & $124.1 \pm 13.1$ & $127.3 \pm 9.8$ & 0.5237 \\
\hline 12 weeks & $124.8 \pm 14.0$ & $122.3 \pm 13.3$ & 0.8795 \\
\hline \multicolumn{4}{|c|}{ DBP (mmHg) } \\
\hline 0 week & $73.8 \pm 5.5$ & $73.3 \pm 7.7$ & 0.8625 \\
\hline 12 week & $76.4 \pm 7.4$ & $68.3 \pm 6.5 *$ & 0.0104 \\
\hline
\end{tabular}

${ }^{1}$ Data are expressed as the mean \pm SD. BMR, basal metabolic rate; SBP, systolic blood pressure; DBP, diastolic blood pressure.

${ }^{2}$ Differences between the two groups in the same week.

* Significantly differs between 0 and 12 weeks in the same group, $p<0.05$.

\section{Effects of SBR on the Body Composition and Serum Adipokine Concentrations}

Body composition and serum adipokine concentration data are presented in Table 6. BF, LBM, total BF, Android, Gynoid, and the $\mathrm{A} / \mathrm{G}$ ratio did not significantly differ at the baseline. At 12 weeks, BF was significantly lower in both groups $(p<0.05)$. Android was reduced in both groups, although the reduction was greater in the SBR group, but there was no significant difference between the SBR and control groups. Gynoid was significantly lower in the SBR group but not the control group $(p<0.05)$. The $\mathrm{A} / \mathrm{G}$ ratio and LBM did not change after SBR intake. 
Table 6: Body composition measured by DEXA and serum adipokine concentrations ${ }^{1}$

\begin{tabular}{|c|c|c|c|}
\hline & Control $(n=11)$ & $\begin{array}{c}\text { Soybean } / \text { brown } \\
\text { rice }(\mathrm{n}=12)\end{array}$ & $\mathrm{p}$ value $^{2}$ \\
\hline \multicolumn{4}{|l|}{ Body fat $(\mathrm{kg})$} \\
\hline 0 week & $23.8 \pm 7.2$ & $22.4 \pm 3.9$ & 0.5795 \\
\hline 12 weeks & $22.7 \pm 8.0 *$ & $21.1 \pm 3.5 *$ & 0.7118 \\
\hline \multicolumn{4}{|c|}{ Lean body mass $(\mathrm{kg})$} \\
\hline 0 week & $36.7 \pm 3.9$ & $36.6 \pm 2.9$ & 0.9761 \\
\hline 12 weeks & $36.5 \pm 3.5$ & $36.8 \pm 3.2$ & 0.6528 \\
\hline \multicolumn{4}{|l|}{ Total body fat (\%) } \\
\hline 0 week & $38.7 \pm 6.2$ & $37.8 \pm 4.5$ & 0.6887 \\
\hline 12 weeks & $37.5 \pm 7.0 *$ & $36.4 \pm 4.5 *$ & 0.0828 \\
\hline \multicolumn{4}{|l|}{ Android (\%) } \\
\hline 0 week & $46.7 \pm 6.3$ & $45.9 \pm 4.3$ & 0.7087 \\
\hline 12 weeks & $44.8 \pm 6.6 *$ & $43.4 \pm 4.1 *$ & 0.7682 \\
\hline \multicolumn{4}{|l|}{ Gynoid (\%) } \\
\hline 0 week & $44.0 \pm 6.2$ & $43.5 \pm 5.5$ & 0.8463 \\
\hline 12 weeks & $42.7 \pm 6.8$ & $41.9 \pm 5.9 *$ & 0.6549 \\
\hline \multicolumn{4}{|l|}{$\mathrm{A} / \mathrm{G}$ ratio } \\
\hline 0 week & $1.07 \pm 0.11$ & $1.06 \pm 0.12$ & 0.8047 \\
\hline 12 weeks & $1.06 \pm 0.13$ & $1.05 \pm 0.18$ & 0.6658 \\
\hline \multicolumn{4}{|l|}{ Leptin (ng/mL) } \\
\hline 0 week & $12.1 \pm 5.8$ & $12.6 \pm 5.6$ & 0.6666 \\
\hline 12 weeks & $9.8 \pm 7.1^{*}$ & $9.7 \pm 5.8$ & 0.9264 \\
\hline \multicolumn{4}{|c|}{ Adiponectin (ng/mL) } \\
\hline 0 week & $14.3 \pm 2.9$ & $14.1 \pm 5.6$ & 0.9214 \\
\hline 12 weeks & $16.8 \pm 3.6 *$ & $16.8 \pm 7.0 *$ & 0.9883 \\
\hline
\end{tabular}

${ }^{1}$ Data are expressed as the mean $\pm \mathrm{SD}$. Android, android fat percentage; Gynoid, gynoid fat percentage; $\mathrm{A} / \mathrm{G}$ ratio, android to gynoid fat percentage ratio.

${ }_{2}^{2}$ Differences between the two groups in the same week.

* Significantly differs between 0 and 12 weeks in the same group, $p<0.05$.

Serum leptin and adiponectin concentrations did not significantly differ between groups at the baseline. The serum leptin concentration was significantly lower in the control group, and the adiponectin concentration was significantly lower in both groups $(p<0.05)$.

\section{Effects of SBR on Blood Lipids Profiles, and Glucose and Insulin Concentrations}

Blood lipid profiles, and glucose and insulin concentration data are shown in Table 7. Serum TC, LDL-C, HDL-C, and TG concentrations did not significantly differ at the baseline. In the SBR group, after ingestion of SBR for 12 weeks, serum TC and LDL-C concentrations were significantly lower $(p<0.05)$. Serum TG concentrations were significantly reduced in both groups $(p<0.05)$, although that of the SBR group was higher than the control, but the difference was non-significant. HDL-C concentrations were higher in both groups. Neither plasma glucose or serum insulin concentrations, nor HOMA-IR or QUICKI had changed.
Table 7: Blood lipid profiles, fasting blood sugar, insulin concentration, insulin resistance, insulin sensitivity, and plasma isoflavone concentrations at the baseline and 12 weeks ${ }^{1}$

\begin{tabular}{|c|c|c|c|}
\hline & Control $(\mathrm{n}=11)$ & $\begin{array}{l}\text { Soybean/brown } \\
\text { rice }(n=12)\end{array}$ & p value ${ }^{2}$ \\
\hline \multicolumn{4}{|c|}{ Total cholesterol (mg/dL) } \\
\hline 0 week & $213.9 \pm 16.0$ & $229.1 \pm 53.3$ & 0.7119 \\
\hline 12 weeks & $207.0 \pm 18.8$ & $206.3 \pm 31.9 *$ & 0.6225 \\
\hline \multicolumn{4}{|c|}{ Triglycerides (mg/dL) } \\
\hline 0 week & $99.5 \pm 25.6$ & $127.6 \pm 40.0$ & 0.0524 \\
\hline 12 weeks & $66.1 \pm 15.0 *$ & $87.3 \pm 26.9 *$ & 0.0421 \\
\hline \multicolumn{4}{|c|}{ LDL-C (mg/dL) } \\
\hline 0 week & $131.8 \pm 17.7$ & $150.1 \pm 44.2$ & 0.3888 \\
\hline 12 weeks & $122.1 \pm 19.1$ & $125.6 \pm 28.8 *$ & 0.8293 \\
\hline \multicolumn{4}{|c|}{ HDL-C (mg/dL) } \\
\hline 0 week & $63.1 \pm 7.9$ & $58.8 \pm 11.2$ & 0.3009 \\
\hline 12 weeks & $69.4 \pm 7.0 *$ & $64.7 \pm 12.9 *$ & 0.8392 \\
\hline \multicolumn{4}{|c|}{ Blood sugar (mg/dL) } \\
\hline 0 week & $96.7 \pm 9.1$ & $102.5 \pm 9.5$ & 0.1509 \\
\hline 12 weeks & $100.9 \pm 6.9$ & $103.6 \pm 11.8$ & 0.2097 \\
\hline \multicolumn{4}{|l|}{ Insulin (mU/L) } \\
\hline 0 week & $6.2 \pm 1.7$ & $9.0 \pm 4.6$ & 0.2069 \\
\hline 12 weeks & $5.9 \pm 1.9$ & $6.6 \pm 2.9$ & 0.4600 \\
\hline \multicolumn{4}{|l|}{ HOMA-IR } \\
\hline 0 week & $1.5 \pm 0.5$ & $2.3 \pm 1.3$ & 0.1757 \\
\hline 12 weeks & $1.5 \pm 0.5$ & $1.7 \pm 0.7$ & 0.2678 \\
\hline \multicolumn{4}{|l|}{ QUICKI } \\
\hline 0 week & $0.36 \pm 0.02$ & $0.35 \pm 0.03$ & 0.2383 \\
\hline 12 weeks & $0.36 \pm 0.02$ & $0.36 \pm 0.04$ & 0.2698 \\
\hline \multicolumn{4}{|c|}{ Isoflavones $(\mathrm{nmol} / \mathrm{L})$} \\
\hline 0 week & $43.3 \pm 14.8$ & $45.8 \pm 32.4$ & 0.8122 \\
\hline 12 weeks & $71.8 \pm 32.3 *$ & $139.3 \pm 93.7 *$ & 0.0342 \\
\hline
\end{tabular}

${ }^{1}$ Data are expressed as the mean \pm SD. LDL-C, low-density lipoprotein cholesterol; HDL-C, high-density lipoprotein cholesterol; HOMA-IR, homeostasis model assessment of insulin resistance; QUICKI, quantitative insulin sensitivity check index.

${ }^{2}$ Differences between the two groups in the same week.

* Significantly differs between 0 and 12 weeks in the same group, $p<0.05$.

\section{Effects of SBR on Plasma Isoflavone Concentrations}

Plasma isoflavone concentrations significantly increased in both the control and SBR groups after 12 weeks of SBR consumption $(p<0.05)$, whereas those of the SBR group were significant higher than those of the control group $(p<0.05)$ (Table 7).

\section{Discussion}

In the present study, under a restricted diet with only $1200 \mathrm{kcal}$ of energy, overweight postmenopausal women were asked to consume SBR as their grains at lunch for 12 weeks, and their BW, BMI, WC, HC, WHR, total body, Android and Gynoid fat percentages were significantly reduced. One study showed that with a low-energy diet, soy protein-based meal replacements produced greater body weight and body fat reductions than a casein-based $\operatorname{diet}^{[16]}$. However, soy protein and isoflavones of soybeans might play an important role. Supplementa- 
tion with $15 \mathrm{~g}$ soy protein and $100 \mathrm{mg}$ isoflavones affected the BW, BMI, and body fat reductions in Chinese postmenopausal women $^{[17]}$. In our study, there were $8.7 \pm 1.2 \mathrm{~g}$ of soy protein and $22.0 \pm 3.0 \mathrm{mg}$ of isoflavones in the SBR supplement; these contents were lower than supplements given in the above study. Although plasma isoflavone concentrations in the SBR group were higher than those of the control group, they ultimately did not affect BW or body fat. Dietary fiber can also reduce body fat. Postmenopausal women ingested a low-fat diet, and the dietary fiber intake increased from 16 to $23 \mathrm{~g}$, BW was reduced by $6 \mathrm{~kg}$, and body fat was reduced by $2.7 \%{ }^{[18]}$. The intake of dietary fiber in the SBR group was higher than that of the control group, but the BW and body fat were not further reduced. We did not use a low-fat diet in this study, so the effects of dietary fiber on body fat may have been limited. At 12 weeks, energy intake levels were respectively reduced to $281.3 \pm 351.2$ and $342.6 \pm 335.1$ $\mathrm{kcal}$ in the control and SBR groups, and body fat was reduced in both groups, but there was no significant difference between groups. So, a low-calorie diet may be the main reason for the reduction in body fat.

In this study, the gynoid fat percentage in the control group tended to decrease but was not significant. And A/G ratio, $\mathrm{HC}$, and WHR exhibited no significant differences between the two groups; therefore, it was assumed that android and gynoid fat levels both decreased in the SBR and control groups. Animal experiments showed that soy protein can increase insulin sensitivity ${ }^{[19]}$. One study indicated that insulin sensitivity was negatively associated with abdominal fat ${ }^{[20]}$. Thus, lowering insulin resistance may result in decreased abdominal fat and may reduce the $\mathrm{A} / \mathrm{G}$ ratio. A study by Katcher et al. reported that by ingesting five servings of whole grains every day, one consumes $13 \mathrm{~g}$ of dietary fiber per $1000 \mathrm{kcal}$, and the abdominal fat percentage was significantly lower than that of the group that consumed refined grains ${ }^{[21]}$. There were three servings of brown rice in the SBR used in this study, and the dietary intake was $21.5 \mathrm{~g}$ (18.7 g per $1000 \mathrm{kcal})$, and total, android, and gynoid fat percentages were all reduced in the SBR group.

Ingestion of SBR for 12 weeks decreased serum TC and LDL-C concentrations. This can possibly be attributed to many cholesterol-lowering components in soybeans, such as soy protein, isoflavones, phytosterol, saponins, and phytate ${ }^{[11]}$. The mechanism through which soy protein affects cholesterol concentrations is that soy protein regulates sterol regulatory element-binding protein (SREBP)-2, a key transcription factor of cholesterol biosynthesis. Thereby, the activity of HMG-CoA reductase and LDL receptors were regulated, and levels of TC and LDL-C were reduced ${ }^{[22]}$.

A meta-analysis study reported that with consumption of $47 \mathrm{~g}$ soy protein per day, serum TC and LDL-C concentrations were reduced ${ }^{[23]}$. Supplementation with $96 \mathrm{mg}$ of isoflavones a day can also decrease the serum LDL-C level, and the reduction was greater in subjects that initially had higher serum cholesterol levels ${ }^{[10]}$. We provided whole soybeans, and despite the fact that the soy protein and isoflavones were not as concentrated as in supplements, the saponins, phytosterol, and phytate in the soybeans can lower the absorption of cholesterol and may have resulted in decreased serum cholesterol concentrations ${ }^{[24,25]}$. On the other hand, dietary fiber can also lower cholesterol absorption in the intestines and increase secondary bile acid excretion $^{[26]}$. Serum TC and LDL-C were reduced in the SBR group which can possibly be attributed to a higher dietary fiber intake.

In conclusion, under a low-calorie diet, overweight postmenopausal women ingested SBR as their grains at lunch, and the $\mathrm{BW}, \mathrm{WC}, \mathrm{HC}, \mathrm{WHR}$, total body fat and android fat percentages, and serum TC and LDL-C concentrations significantly decreased. These would have favorable effects on lowering risks of cardiovascular disease.

\section{Acknowledgment:}

We would like to thank all subjects for participating in this study. This study was provided by grant 100TMU-SHH-09.

\section{References}

1. Ozbey, N., Sencer, E., Molvalilar, S., et al. Body fat distribution and cardiovascular disease risk factors in pre- and postmenopausal obese women with similar BMI. (2002) Endocr J 49(4): 503-509.

2. Preis, S. R., Massaro, J. M., Robins, S. J., et al. Abdominal Subcutaneous and Visceral Adipose Tissue and Insulin Resistance in the Framingham Heart Study. (2010) Obesity (Silver Spring) 18(11): 2191-2198. 3. Shifren, J. L., Schiff, I. Role of hormone therapy in the management of menopause. (2010) Obstet Gynecol 115(4): 839-855.

4. Weiderpass, E., Adami, H. O., Baron, J. A., et al. Risk of endometrial cancer following estrogen replacement with and without progestins. (1999) J Natl Cancer Inst 91(13): 1131-1137.

5. Goodman-Gruen, D., Kritz-Silverstein, D. Usual dietary isoflavone intake and body composition in postmenopausal women. (2003) Menopause $10(5)$ : 427-432.

6. Villegas, R., Gao, Y. T., Yang, G., et al. Legume and soy food intake and the incidence of type 2 diabetes in the Shanghai Women's Health Study. (2008) Am J Clin Nutr 87(1): 162-167.

7. Cederroth, C. R., Nef, S. Soy, phytoestrogens and metabolism: A review. (2009) Mol Cell Endocrinol 304(1-2): 30-42.

8. Penza, M., Montani, C., Romani, A., et al: Genistein affects adipose tissue deposition in a dose-dependent and gender-specific manner. (2006) Endocrinology 147(12): 5740-5751.

9. Jayagopal, V., Albertazzi, P., Kilpatrick, E. S., et al. Beneficial effects of soy phytoestrogen intake in postmenopausal women with type 2 diabetes. Diabetes Care 25(10): 1709-1714.

10. Zhuo, X. G., Melby. M. K., Watanabe, S. Soy isoflavone intake lowers serum LDL cholesterol: a meta-analysis of 8 randomized controlled trials in humans. (2004) J Nutr 134(9): 2395-2400.

11. Potter, S. M. Overview of proposed mechanisms for the hypocholesterolemic effect of soy. (1995) J Nutr 125(3 Suppl): 606S-611S.

12. Saltzman, E., Das, S. K., Lichtenstein, A. H., et al. An oat-containing hypocaloric diet reduces systolic blood pressure and improves lipid profile beyond effects of weight loss in men and women. (2001) J Nutr 131(5): 1465-1470.

13. Steffen, L. M., Jacobs, D. R. Jr., Murtaugh, M. A., et al. Whole grain intake is associated with lower body mass and greater insulin sensitivity among adolescents. (2003) Am J Epidemiol 158(3): 243-250.

14. Sahyoun, N. R., Jacques, P. F., Zhang, X. L., et al. Whole-grain intake is inversely associated with the metabolic syndrome and mortality in older adults. (2006) Am J Clin Nutr 83(1): 124-131.

15. Anupongsanugool, E., Teekachunhatean, S., Rojanasthien N, et al. Pharmacokinetics of isoflavones, daidzein and genistein, after ingestion of soy beverage compared with soy extract capsules in postmenopausal Thai women. (2005) BMC Clin Pharmacol 5: 2.

16. Allison, D. B., Gadbury, G., Schwartz, L. G., et al. A novel soy-based meal replacement formula for weight loss among obese individuals: a randomized controlled clinical trial. (2003) Eur J Clin Nutr 57(4): 514-522. 17. Liu, Z. M., Ho, S. C., Chen, Y. M., et al. A mild favorable effect of soy protein with isoflavones on body composition--a 6-month double-blind randomized placebo-controlled trial among Chinese postmenopausal women. (2010) Int J Obes (Lond) 34(2): 309-318. 
18. Mueller-Cunningham, W. M., Quintana, R., Kasim-Karakas, S. E. An ad libitum, very low-fat diet results in weight loss and changes in nutrient intakes in postmenopausal women. (2003) J Am Diet Assoc 103(12): 1600-1606.

19. Lavigne, C., Marette, A., Jacques, H. Cod and soy proteins compared with casein improve glucose tolerance and insulin sensitivity in rats. (2000) Am J Physiol Endocrinol Metab 278(3): E491-500.

20. Sites, C. K., Calles-Escandon, J., Brochu, M., et al. Relation of regional fat distribution to insulin sensitivity in postmenopausal women. (2000) Fertil Steril 73(1): 61-65.

21. Katcher, H. I., Legro, R.S., Kunselman, A. R., et al. The effects of a whole grain-enriched hypocaloric diet on cardiovascular disease risk factors in men and women with metabolic syndrome. (2008) Am J Clin Nutr 87(1): 79-90.
22. Torres, N., Torre-Villalvazo, I., Tovar, A. R. Regulation of lipid metabolism by soy protein and its implication in diseases mediated by lipid disorders. (2006) J Nutr Biochem 17(6): 365-373.

23. Anderson, J. W., Johnstone, B. M., Cook-Newell, M. E. Meta-analysis of the effects of soy protein intake on serum lipids. (1995) N Engl J Med 333(5): 276-282.

24. Lee, S. O., Simons, A. L., Murphy, P. A., et al. Soyasaponins lowered plasma cholesterol and increased fecal bile acids in female golden Syrian hamsters. (2005) Exp Biol Med (Maywood) 230(7): 472-478.

25. Miettinen, T. A., Puska, P., Gylling, H., et al. Reduction of serum cholesterol with sitostanol-ester margarine in a mildly hypercholesterolemic population. (1995) N Engl J Med 333(20): 1308-1312.

26. Brown, L., Rosner, B., Willett, W. W., et al. Cholesterol-lowering effects of dietary fiber: a meta-analysis. (1999) Am J Clin Nutr 69(1): $30-42$.
Online ISSN: $2377-0619$

Journal Title: International Journal Food and Nutritional Science Journal Short Name: Int J Food Nutr Sci
Ommega Online Publishers

E-mail: editor.foodscience@ommegaonline.com Website: www.ommegaonline.com 